\title{
An endothelialized urothelial cell-seeded tubular graft for urethral replacement
}

\author{
Annie Imbeault, MD; ${ }^{*}$ Geneviève Bernard, MSc; ${ }^{\dagger}$ Alexandre Rousseau, BSc; ${ }^{*+}$ Amélie Morissette, BSc; ${ }^{*+}$ \\ Stéphane Chabaud, PhD; ${ }^{\dagger}$ Sara Bouhout, MSc, ${ }^{*+}$ Stéphane Bolduc, MD ${ }^{*+}$
}

*Département de Chirurgie, Faculté de Médecine, Université Laval, Québec, QC; ${ }^{+}$Centre LOEX de I'Université Laval, Génie tissulaire et régénération : LOEX du Centre de recherche FRQS du Centre de recherche de CHU de Québec, QC

Cite as: Can Urol Assoc J 2013;7(1):E4-E9. http://dx.doi.org/10.5489/cuaj.12217

\section{Abstract}

Introduction: Many efforts are used to improve surgical techniques and graft materials for urethral reconstruction. We developed an endothelialized tubular structure for urethral reconstruction.

Methods: Two tubular models were created in vitro. Human fibroblasts were cultured for 4 weeks to form fibroblast sheets. Then, endothelial cells (ECs) were seeded on the fibroblast sheets and wrapped around a tubular support to form a cylinder for the endothelialized tubular urethral model (ET). No ECs were added in the standard tubular model (T). After 21 days of maturation, urothelial cells were seeded into the lumen of both models. Constructs were placed under perfusion in a bioreactor for 1 week. At several times, histology and immunohistochemistry were performed on grafted nude mice to evaluate the impact of ECs on vascularization.

Results: Both models produced an extracellular matrix, without exogenous material, and developed a pseudostratified urothelium. Seven days after the graft, mouse red blood cells were present only in the outer layers in T model, but in the full thickness of ET model. After 14 days, erythrocytes were present in both models, but in a greater proportion in ET model. At day 28, both models were well-vascularized, with capillary-like structures in the whole thickness of the tubes.

Conclusion: Incorporating endothelial cells was associated with an earlier vascularization of the grafts, which could decrease the necrosis of the transplanted tissue. As those models can be elaborated with the patient's cells, this tubular urethral graft would be unique in its autologous property.

\section{Introduction}

Treating complex urethral strictures and repairing severe hypospadias remain a challenging problem in urology. Several tissues have been used for urethral reconstruction, including genital and extragenital skin flaps, buccal and lingual mucosa and tunica vaginalis. ${ }^{1-5}$ Buccal mucosa is one of the most widely used extragenital tissues for urethral reconstruction and has been associated with good results. ${ }^{6,7}$
However, several complications like pain, numbness, injury to salivary duct and submucosal scarring have been reported, which could limit its use as a substitution material. ${ }^{8,9}$

To overcome this problem, current research has focused on developing alternative materials like exogenic bioscaffolds. The evolution of tissue engineering has led to the use of extracellular matrices (ECM), such as small intestine submucosa (SIS), pericardium, bladder submucosa (BSM) and acellular corpus spongiosum matrix for urethral replacement. ${ }^{10-12}$ Interesting results are emerging in the literature, including development of preseeded bioscaffold models. ${ }^{13}$ However, despite complex decellularization and sterilization methods, a significant portion of residual DNA could still be retained in those exogenic materials. ${ }^{14}$ Biosafety and immune response are still important considerations and preoccupations.

Another problem encountered during graft is vascularization. A rapid reperfusion is a key to a successful graft. A lack of nutriments and oxygen can lead to necrosis and transplant failure. This is an important obstacle to the development of a reconstructed tissue in vitro for clinical application. As demonstrated for skin, endothelial cells (ECs) seeding can help to resolve this problem by reconstructing a capillary network in the tissue before implantation. ${ }^{15-17}$ The self-assembly method is a novel approach to reconstruct urological tissues. ${ }^{18-21}$ In this method, cells produce their own ECM without the use of exogenous material. In a clinical context, cells come from the patient to be transplanted; therefore, the risk of immune response to the graft is strongly decreased. Moreover, ECs can easily be added to this matrix to form a capillary network in the reconstructed tissue. ${ }^{15,19}$

Contrary to other urethral replacement models, the selfassembly method allows the development of an endothelialized tubular structure with a pseudostratified urothelium, which could be used for urethral reconstructive surgery. 


\section{Methods}

\section{Fibroblasts, urothelial and endothelial cells isolation}

Human dermal fibroblasts (DFs) were isolated from human skin biopsies after breast reductive surgeries as previously described. ${ }^{22}$ Cells were cultured in Dulbecco-Vogt modified Eagle medium (DMEM; Invitrogen, Burlington, Ontario, Canada), supplemented with $10 \%$ fetal bovine serum (FBS; Hyclone, Fisher Scientific, Ottawa, Ontario, Canada), $100 \mathrm{U} / \mathrm{mL}$ penicillin G (Sigma, Oakville, Canada) and 25 нg/ $\mathrm{mL}$ gentamicine (Schering, Pointe-Claire, Quebec, Canada) and incubated in $8 \% \mathrm{CO}_{2}$ at $37^{\circ} \mathrm{C}$ (DF medium).

Urothelial cells (UCs) were obtained from a small human cadaveric bladder biopsy as previously described. ${ }^{23}$ Cells were cultured with irradiated fibroblasts in DMEM-Ham supplemented with $10 \% \mathrm{FBS}, 5 \mu \mathrm{g} / \mathrm{mL}$ insulin (Sigma), $0.4 \mu \mathrm{g} / \mathrm{mL}$ hydrocortisone (Calbiochem, San Diego, CA), $10^{-10} \mathrm{M}$ cholera toxin (Sigma), $10 \mu \mathrm{g} / \mathrm{ml}$ epidermal growth factor (Austral Biologicals, San Ramon, CA), $100 \mathrm{U} / \mathrm{mL}$ penicillin and $25 \mu \mathrm{g} / \mathrm{mL}$ gentamicin and incubated in $8 \% \mathrm{CO}_{2}$ at $37^{\circ} \mathrm{C}$ (UC medium).

Human umbilical vein endothelial cells (HUVEC or ECs) were obtained from healthy newborns by enzymatic digestion with $0.250 \mu \mathrm{g} / \mathrm{mL}$ thermolysin (Sigma). After a process already described,,$^{15} \mathrm{ECs}$ were suspended in EBM-2 medium (Clonetics, San Diego, CA) containing 2\% SVF, $100 \mathrm{U} / \mathrm{mL}$ of penicillin $\mathrm{G}$ and $25 \mu \mathrm{g} / \mathrm{mL}$ of gentamicin, vascular endothelial growth factor (VEGF), recombinant human basic fibroblast growth factor (rhFGF-B), recombinant human epidermal growth factor (rhEGF), insulin and ascorbic acid (EC medium).

\section{Tubular structure preparation}

DFs were seeded at a concentration of $1.2 \times 10^{4}$ cells $/ \mathrm{cm}^{2}$ in DF medium and supplemented with $50 \mu \mathrm{g} / \mathrm{mL}$ of ascorbic acid to form a fibroblast sheet. At day 25, ECs were seeded on DFs sheets at a concentration of $1.2 \times 10^{4} \mathrm{cells} / \mathrm{cm}^{2}$ to obtain the endothelialized tubular urethral model (ET model). No ECs were seeded on the DFs sheets for the standard tubular model ( $T$ model). Sheets were then cultured in an equal volume of DF and EC media with $50 \mu \mathrm{g} / \mathrm{mL}$ of ascorbic acid.

At day 27, DFs and DFs/ECs sheets were rolled around a plastic support $(6.5 \mathrm{~mm}$ in diameter) to form a tubular structure. Tubes were cultured in an equal volume of EC medium and DMEM-Ham containing 10\% FetalClone II serum (Hyclone), $100 \mathrm{U} / \mathrm{mL}$ penicillin, $25 \mu \mathrm{g} / \mathrm{mL}$ gentamicin and $50 \mu \mathrm{g} / \mathrm{mL}$ of ascorbic acid. Both models were cultured for 21 days to allow fusion of the layers.
After maturation, both models were placed in a chamber allowing the separation of the internal and external culture media. Intraluminal cell seeding was performed using a technique previously described. ${ }^{24}$ About 3 millions of UCs were inserted in the luminal space of each tube. Chambers were placed onto a bottle-roller (Wheaton Instruments, Millville, $\mathrm{NJ})$ at low speed (about $1 \mathrm{rpm}$ ) to allow uniform seeding of UCs. Tubes were then placed in a custom-made bioreactor (Ismatek pump, Cole-Parmer Canada Inc., Montreal, Quebec, Canada) to allow intraluminal flow of UC medium. The external culture medium was the same as the one used for maturation of the models. Tubes were kept in a humidified incubator with $8 \% \mathrm{CO}_{2}$ at $37^{\circ} \mathrm{C}$ for a week.

\section{In vivo subcutaneous implantation}

All experiments were carried out in accordance with the ethical standards of our institutional committee on animal experimentation. Subcutaneous implantation technique was performed as previously described. ${ }^{25}$ Briefly, a 10 Fr Foley catheter segment was inserted into each tubular structure before implantation to prevent tube from collapsing. Male athymic nu/nu mice (Charles River Laboratories, Lasalle, Quebec, Canada) were anesthetized using Isoflurane USP (Schein Pharmaceutical, Etobicoke, Ontario, Canada). Buprenorphine (Buprenex, Reckitt Benckiser Healthcare, UK) was used for local anesthesia. After a 3-cm dorsal skin incision and subcutaneous connective tissue excision, both tubular models were positioned on the dorsal muscle of the mouse, one T model on the left side and one ET model on the right side of the median line. To evaluate the vascularization process, mice were sacrificed 7,14 and 28 days after the graft.

\section{Histological and immunohistochemical analysis}

Analyses were performed before implantation and at each sacrifice for both models. Sections of each model were fixed in $10 \%$ buffered formalin and embedded in paraffin. Histology sections $(5 \mu \mathrm{m})$ were stained with Masson's trichrome. For immunofluorescence staining, sections were embedded in OCT compound (Somengen, Edmonton, Alberta, Canada). Frozen sections of the tubes $(5 \mu \mathrm{m})$ were fixed for 10 minutes and then incubated for 45 minutes with primary antibodies (Table 1). As negative control, primary antibodies were omitted. Secondary antibodies were coupled to Alexa-594. Nuclei were counterstained with Hoechst. The results were viewed using an Axio Imager M2 microscope (Carl Zeiss Canada Ltd., Toronto, Ontario, Canada) and images were processed with Axiovision 4.8.2 software. 
Imbeault et al.

\section{Results}

\section{Characterization of T and ET models}

Histological staining was performed on $\mathrm{T}$ and ET models before implantation and at different time points to evaluate the integrity of the urothelium and the extracellular matrix (ECM) (Fig. 1). A pseudostratified urothelium was always present on the luminal surface of the tubes. A dense ECM and a good cohesion between layers in T and ET models were also observed. Contrary to what was observed in the T model (Fig. 1, part A), capillaries formed by human ECs were observed in the ET model before implantation (Fig. 1, part B). At day 7 after grafting, capillaries were present in both models and both models had already merged with mouse subcutaneous tissues (Fig. 1, parts C and D).

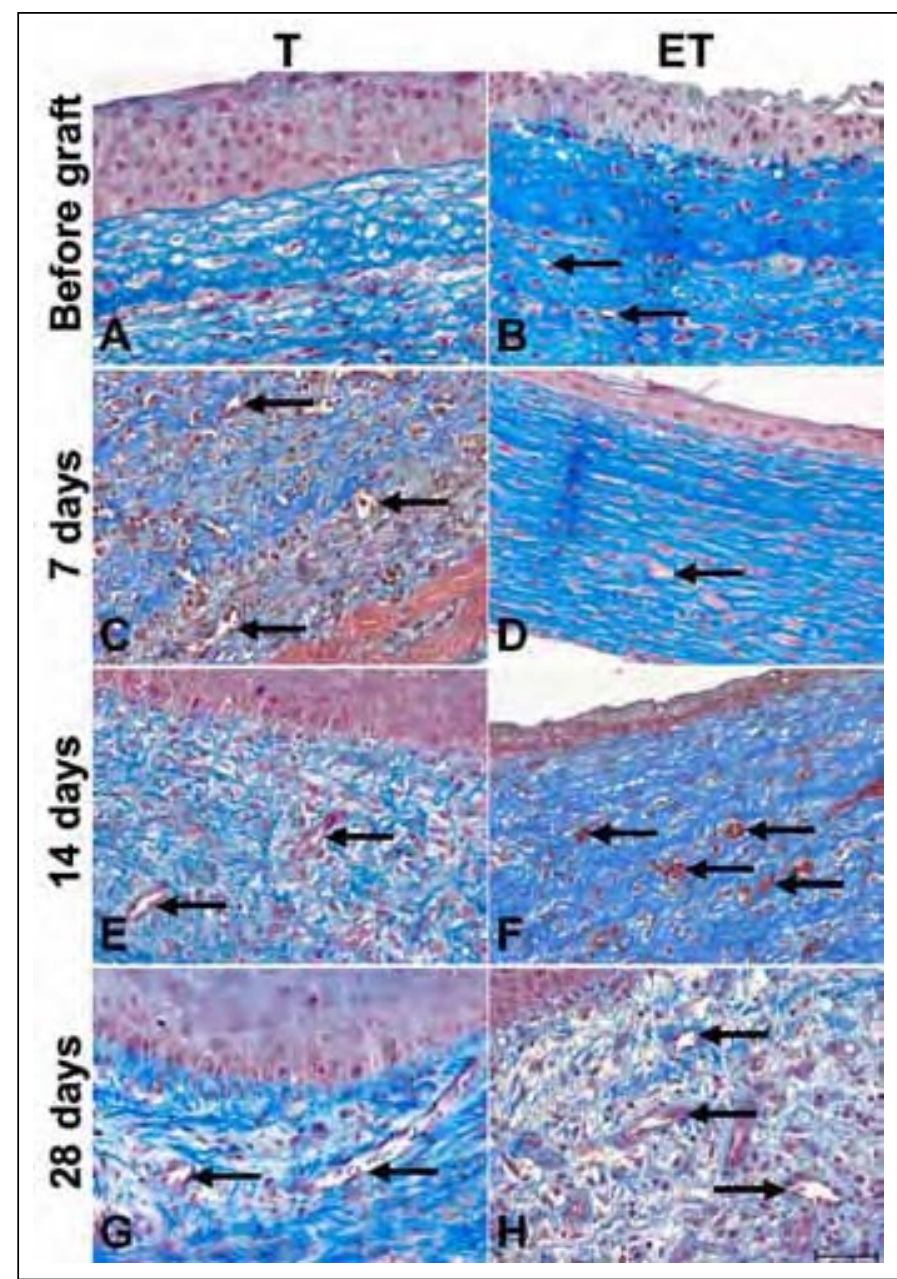

Fig. 1. Histological characterization of $T$ and ET models. Masson's trichrome histological staining of $\mathrm{T}$ (left column) and $\mathrm{ET}$ (right column) models before implantation (A-B) and after each sacrifice: 7 days (C-D), 14 days (E-F) and 28 days (G-H). Presence of a pseudostratified urothelium was observed in both models. Capillaries were seen in the ET model before implantation and in both models after (capillaries are pointed by black arrows). Scale bar: $50 \mu \mathrm{m}$.

\begin{tabular}{lcc}
\hline \multicolumn{3}{l}{ Table 1. The primary antibodies } \\
\hline Specificity & Dilution & Source \\
\hline Keratin 8/18 & $1: 100$ & ARP \\
Laminin & $1: 200$ & Abcam \\
Collagen I & $1: 400$ & Calbiochem \\
Mouse red-blood cell & $1: 800$ & Cedarlane \\
Human PECAM-1 & $1: 400$ & R\&D Systems \\
Mouse PECAM-1 & $1: 800$ & Pharmingen \\
\hline PECAM: platelet endothelial cell adhesion molecule; ARP: American Research Products.
\end{tabular}

Moreover, mouse erythrocytes were seen in the ET model as soon as 14 days after implantation (Fig. 1, part F).

Immunohistochemical analyses showed that both models contained collagen type I (Col-I), the most important ECM component (Fig. 2, parts A and B). Presence of urothelium was confirmed by cytokeratin 8/18 (CK8/18), an epithelial marker (Fig. 2, parts C and D). Analyses for Col-I and CK8/18 were also performed at 7,14 and 28 days with no significant differences (data not shown).

Basal membrane is very important to establish the urothelium. Laminin, a component of this membrane, could be shown in T (Fig. 3, part A) and ET models (Fig. 3, part B) before implantation and at each sacrifice time (Fig. 3, parts $\mathrm{C}$ to $\mathrm{H}$ ). Moreover, as expected, laminin was also present in the wall of capillaries. Human capillaries can be seen in the ET model before implantation (Fig. 3, part B). Due to the lack of specificity of the used antibody for the human protein, mouse capillaries could also be seen in both models at day 7,14 and 28 after implantation (Fig. 3, parts $\mathrm{C}$ to $\mathrm{H}$ ).

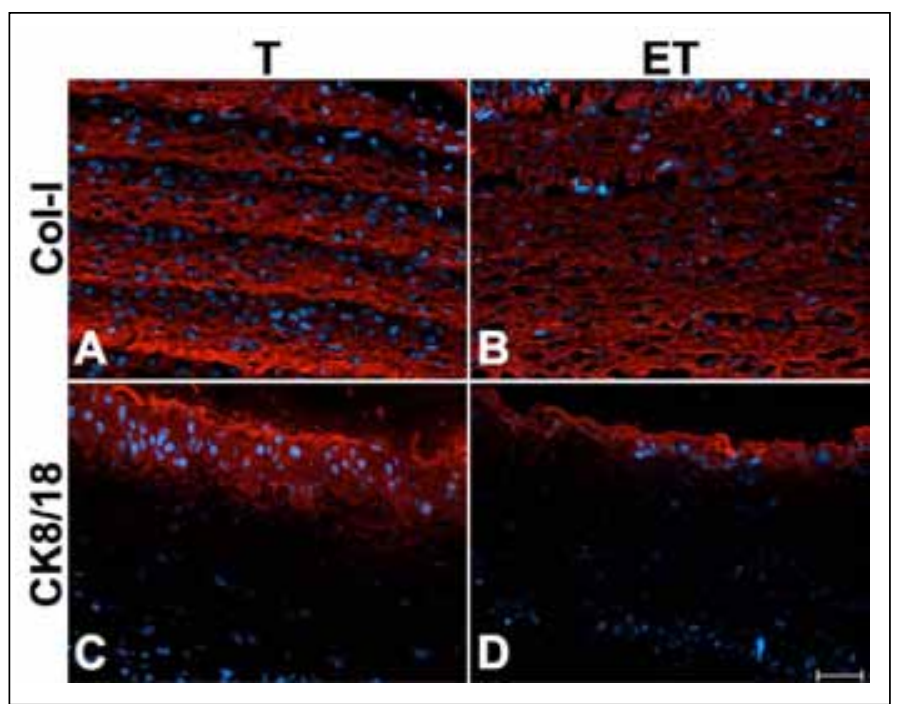

Fig. 2. Characterization of ECM and urothelium. Immunofluorescence of Col-I (A-B) and CK8/18 (C-D) of T (left column) and ET (right column) models before implantation. Col-1, an important component of the ECM, and CK8/18, an epithelial marker, were present in both models. Antibodies are illustrated in red and nuclei in blue. Scale bar: $50 \mu \mathrm{m}$. 


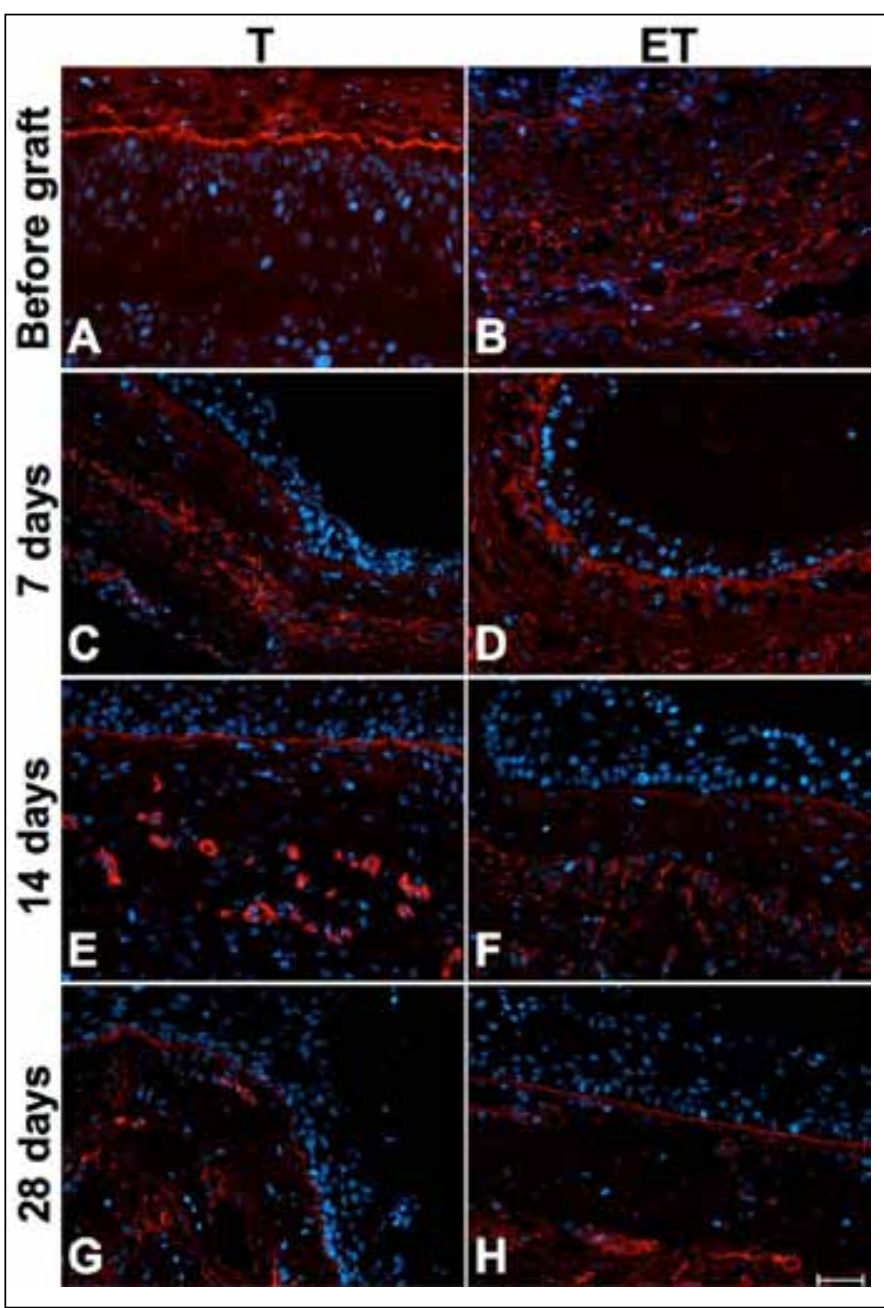

Fig. 3. Characterization of T and ET models with laminin staining. Immunofluorescence of laminin of T model (left column) and ET model (right column) before implantation (A-B) and after each sacrifice: 7 days (C-D), 14 days (E-F) and 28 days $(\mathrm{G}-\mathrm{H})$. Basal membrane was present at the junction of stroma and urothelium. Laminin was also observed in human and mouse capillaries walls. Laminin is illustrated in red and nuclei in blue. Scale bar: $50 \mu \mathrm{m}$.

\section{Revascularization analysis}

Immunohistochemical analyses were performed to determine the impact of ECs into our tubular urethral models. Whereas anti-human platelet endothelial cell adhesion molecule (PECAM-1) was always negative in the T model where no ECs were incorporated before implantation (Fig. 4, part A, Fig. 5, part A, Fig. 6, part A), the presence of human ECs into ET model was confirmed with positive anti-human PECAM-1 before implantation (not shown) and at 7 (Fig. 4, part B), 14 (Fig. 5, part B) and 28 days (Fig. 6, part B). At 7 days, mouse ECs were similarly found in both models (Fig. 4, parts $\mathrm{C}$ and $\mathrm{D})$. However, mouse red blood cells were observed in the external layers of the T model (Fig. 4, part E) in opposition to the ET model where they were found in the whole structure of the tube (Fig. 4, part F). At 14 days after implantation, we observed mouse capillaries (Fig. 5, parts C

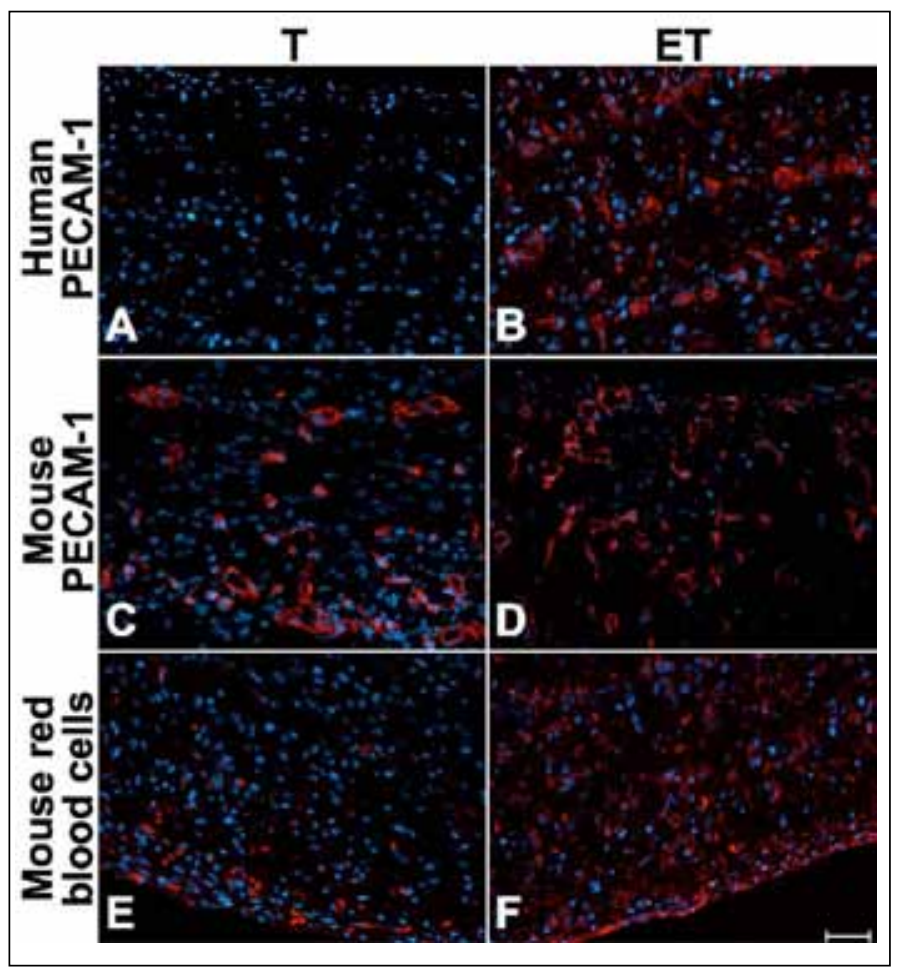

Fig. 4. Short-term characterization (7 days after grafting) of T and ET models. Immunofluorescence of human PECAM-1 (A-B), mouse PECAM-1 (C-D) and mouse red blood cells (E-F) for T (left column) and ET models (right column), at 7 days. Presence of mouse capillaries was similar in both models, but mouse red blood cells were located at the periphery of the T model. In the ET model, human capillaries and mouse red blood cells were present throughout the tube. Antibodies are illustrated in red and nuclei in blue. Scale bar: $50 \mu \mathrm{m}$.

and D) and red blood cells (Fig. 5, parts E and F) throughout the thickness of both models, but mouse erythrocytes were in greater proportion in the ET model (Fig. 5, part F). Longterm implantation (28 days) showed larger mouse capillaries than those observed at 14 days for both models (Fig. 6 , parts $\mathrm{C}$ and $\mathrm{D})$. Also, mouse erythrocytes were present in a substantial proportion in the whole thickness of tubes (Fig. 6, parts $\mathrm{E}$ and F).

\section{Discussion}

In recent years, tissue-engineering techniques have considerably progressed to develop new graft materials for urethral reconstruction. Many efforts have been done to create biomaterials that could be used for complex urethral reconstruction, especially for patients with long-segment defects. In this study, we created an endothelialized tubular graft free of exogenous extracellular matrices.

The ideal biomaterial has to be completely biocompatible without generating immunological response. Many researchers have focused, for the last 2 decades, on the development of exogenous acellular matrices. However, even if those models are submitted to a decellularization and a sterilization process, exogenous ECM materials still retain 


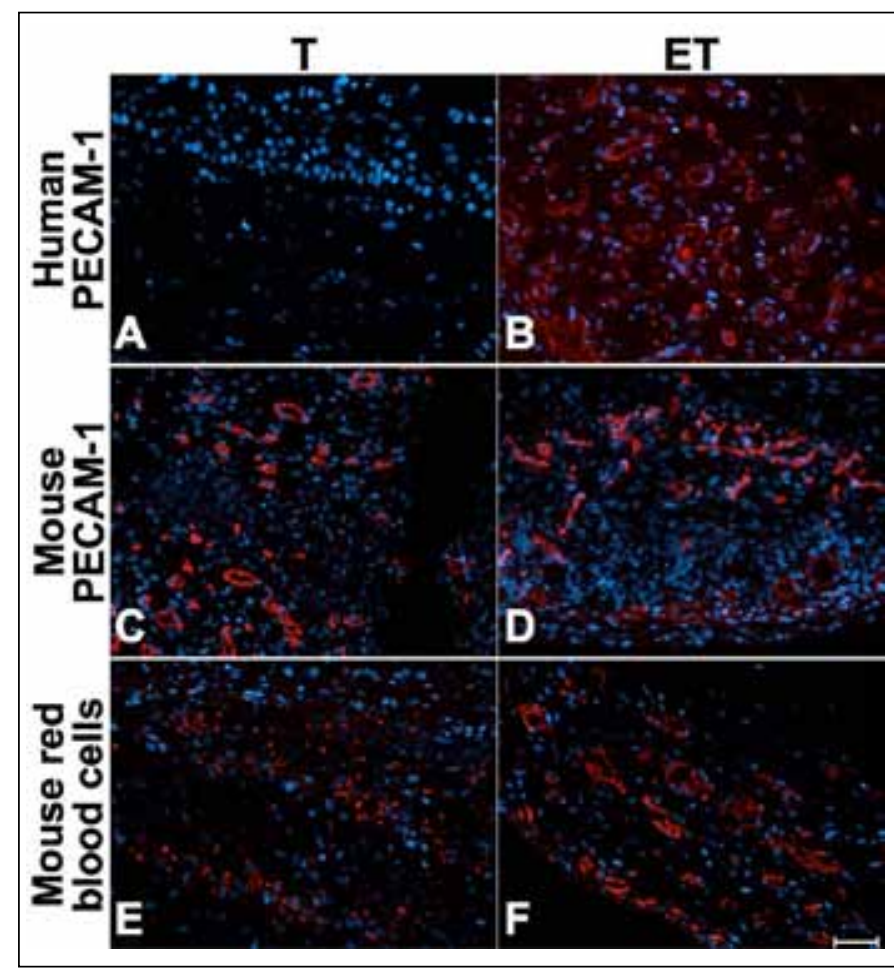

Fig. 5. Mid-term characterization (14 days after grafting) of T and ET models. Immunofluorescence of human PECAM-1 (A-B), mouse PECAM-1 (C-D) and mouse red blood cells (E-F) for T (left) and the ET model (right column), at 14 days. Mouse red blood cells were predominant in ET models. Antibodies are illustrated in red and nuclei in blue. Scale bar: $50 \mu \mathrm{m}$.

a significant portion of residual DNA that could affect biocompatibility. ${ }^{14}$ Feil and colleagues detected porcine DNA residues in commercially available SIS and demonstrated cytotoxic effects on urothelial cells seeded on the scaffold. ${ }^{14}$ Several preparation and transformation methods used before implantation could also affect other model properties, such as mechanical strength and structural morphology. ${ }^{26,27}$ In this study, we used the self-assembly method to produce $T$ and ET models. We observed, by histological and immunohistochemical analysis, a dense ECM completely produced by fibroblasts. In opposition to all exogenous scaffolds models, our models could be autologous, which is a real advantage by eliminating the biocompatibility concerns. The absence of immunological response should reduce the inflammatory and fibrotic reactions and consequently improve the success rate of the procedure.

Diffusion of nutrients and oxygen through the graft is critical after a grafting procedure, but can be limited in some instances, especially when biomaterials are used. Several common complications, such as strictures and urethrocutaneous fistula, are directly linked to insufficient blood supply to the graft. ${ }^{28}$ Guan and colleagues developed a urethral graft made of acellular matrix pre-seeded with rabbit bladder urothelial cells modified with human vascular endothelial growth factor $\left(\mathrm{VEGF}_{165}\right)$ gene to improve vascularization. ${ }^{28}$

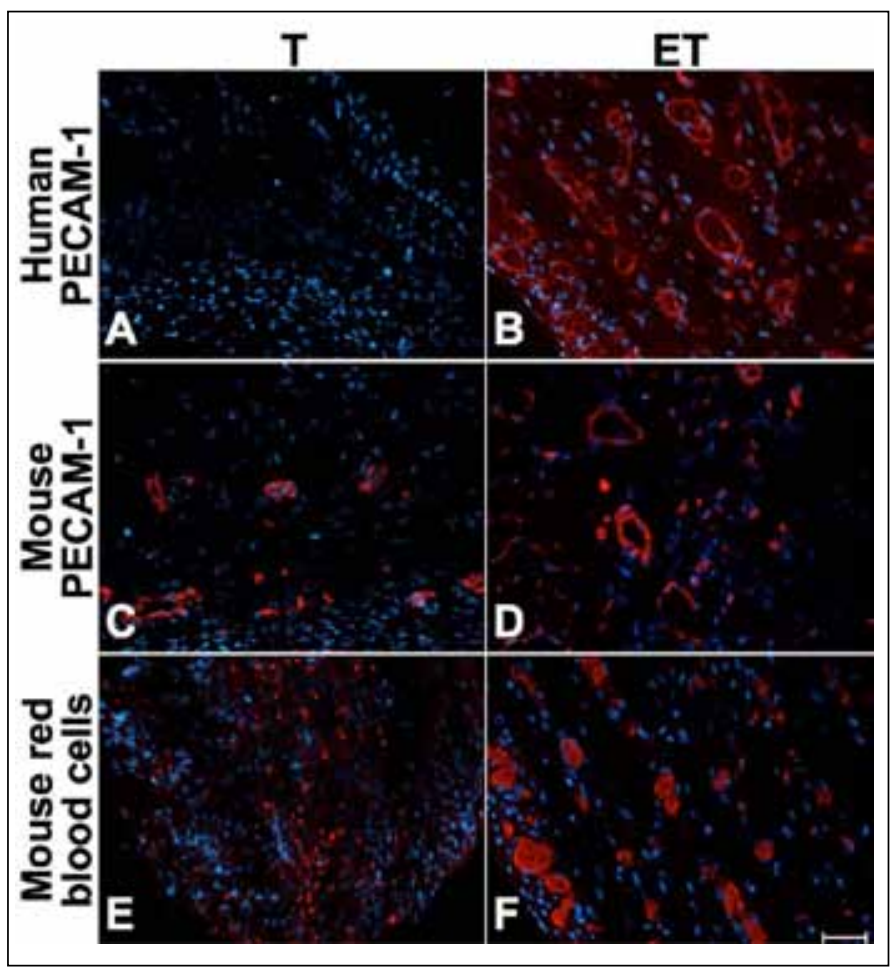

Fig. 6. Long-term characterization (28 days after grafting) of $T$ and ET models. Immunofluorescence of human PECAM-1 (A-B), mouse PECAM-1 (C-D) and mouse red blood cells (E-F) for T (left) and ET models (right column), at 28 days. Mouse red-blood cells were present all over both models, but in a greater proportion in the ET model. Antibodies are illustrated in red and nuclei in blue. Scale bar: $50 \mu \mathrm{m}$.

VEGF-modified graft was associated with a 5- to 6-fold greater abundance of microvessels and also presented an enhanced urothelial layer at 1 month compared to standard graft. However, clinical application of this technique is limited by the complexity of the procedure. Moreover, the risk of insertional mutagenesis by using a retrovirus as a vector for gene delivery is unknown.

To improve vascularization of our tubular graft models, we developed an endothelialized tubular structure. With the self-assembly method, ECs can easily be added to the fibroblast sheet and spontaneously form a human capillarylike network. ${ }^{29,30}$ We demonstrated that the impact of ECs was more noticeable in the early post-grafting period. The ET model was more rapidly vascularized, as observed on immunohistological analysis. Indeed, 7 days after implantation, mouse red blood cells were located at the periphery of the T model, while in the ET model we found erythrocytes throughout the thickness of the tube. As the mouse capillaries were similar for the two models, we can conclude that the higher vascularization of the ET model is due to the presence of a human capillary network before implantation. Prior studies have confirmed that incorporation of ECs into grafts led to an earlier inosculation phenomenon (connection of the graft network with the host's capillaries). ${ }^{15,24}$ The creation 
of a capillary-like network into the tissue-engineered model before implantation enhances earlier vascularization of the graft, thus potentially decreases the risk of ischemia, necrosis and fibrosis. ${ }^{15,29,31}$ After 14 and 28 days, mouse red blood cells were present in the whole thickness of both models, but in a greater proportion in the ET model. This could be a consequence of the early vascularization observed at 7 days after implantation. Also, the urothelium is still present 28 days after implantation with a continued basal membrane. In a clinical context, ECM would not be in direct contact with urine, which would protect the tissue from fibrosis.

\section{Conclusion}

The incorporation of endothelial cells was associated with an earlier vascularization of the graft. This tissue-engineered tubular urethral graft is unique by its possibility to be autologous, contrarily to other tissues actually available. In the future, we are planning to evaluate the success of our models with grafting procedures on rabbit urethras.

Acknowledgements: The authors thank Robert Gauvin and the LOEX team for useful discussions. This study was supported by grants from the Fonds de la Recherche en Santé du Québec and the Canadian Institutes of Health Research. This project was specifically supported by a grant from the Astellas Research Competition. This tissue engineering program initially became possible when Dr. Bolduc was awarded the Canadian Urological Association Scholarship Fund (CUASF).

Competing interests: None declared.

This paper has been peer-reviewed.

\section{References}

1. Fu Q, Deng CL. Ten-year experience with composite bladder mucosa-skin grafts in hypospadias repair. Urology 2006;67:1274-7; discussion 1277. http://dx.doi.org/10.1016/i.urology.2005.12.048

2. Bhargava $S$, Patterson JM, Inman RD, et al. Tissue-engineered buccal mucosa urethroplasty-clinical outcomes. Eur Urol 2008;53:1263-9. http://dx.doi.org/10.1016/i.eururo.2008.01.061

3. Ehrlich RM, Alter $G$. Split-thickness skin graft urethroplasty and tunica vaginalis flaps for failed hypospadias repairs. J Urol 1996;155:131-4. http://dx.doi.org/10.1016/S0022-5347(01)66568-6

4. Song $\amalg, X u Y M$, Hu $X Y$, et al. Urethral substitution using autologous lingual mucosal grafts: an experimental study. BJU Int 2008;101:739-43. http://dx.doi.org/10.1111/i.1464-410X.2007.07230.x

5. Barbagli G, Selli C, Tosto A, et al. Dorsal free graft urethroplasty. J Urol 1996;155:123-6. http://dx.doi. org/10.1016/S0022-5347(01)66566-2

6. Waxman SW, Morey AF. Management of urethral strictures. Lancet 2006;367:1379-80. http://dx.doi. org/10.1016/50140-6736(06)68592-9

7. Cheng EY, Kropp BP. Urologic tissue engineering with small-intestinal submucosa: potential clinical applications. World J Urol 2000;18:26-30. http://dx.doi.org/10.1007/PL00007071

8. Nelson CP, Bloom DA, Kinast $R$, et al. Long-term patient reported outcome and satisfaction after oral mucosa graft urethroplasty for hypospadias. J Urol 2005;174:1075-8. http://dx.doi.org/10.1097/01. ju.0000169421.27043.f2

9. Lauer G, Schimming R, Frankenschmidt A. Intraoral wound closure with tissue-engineered mucosa: new perspectives for urethra reconstruction with buccal mucosa grafts. Plast Reconstr Surg 2001;107:25-33. http://dx.doi.org/10.1097/00006534-200101000-00005
10. Fu Q, Deng CL, Liu W, et al. Urethral replacement using epidermal cell-seeded tubular acellular bladder collagen matrix. BJU Int 2007;99:1162-5. http://dx.doi.org/10.1111/j.1464-410X.2006.06691.x

11. Santucci RA, Barber TD. Resorbable extracellular matrix grafts in urologic reconstruction. Int Braz J Urol 2005;31:192-203. http://dx.doi.org/10.1590/S1677-55382005000300002

12. El-Assmy A, El-Hamid MA, Hafez AT. Urethral replacement: a comparison between small intestinal submucosa grafts and spontaneous regeneration. BJU Int 2004;94:1132-5. http://dx.doi.org/10.1111/ j.1464-410X.2004.05115.X

13. Raya-Rivera A, Esquiliano DR, Yoo JJ, et al. Tissue-engineered autologous urethras for patients who need reconstruction: an observational study. Lancet 201 1;377:1 175-82. http://dx.doi.org/10.1016/ S0140-6736(10)62354-9

14. Feil $G$, Christ-Adler $M$, Maurer $S$, et al. Investigations of urothelial cells seeded on commercially available small intestine submucosa. Eur Urol 2006;50:1330-7. http://dx.doi.org/10.1016/i. eururo.2006.05.041

15. Tremblay PL, Hudon V, Berthod F, et al. Inosculation of tissue-engineered capillaries with the host's vasculature in a reconstructed skin transplanted on mice. Am J Transplant 2005;5:1002-10. http:// dx.doi.org/10.1111/i.1600-6143.2005.00790.x

16. Schechner IS, Crane SK, Wang F, et al. Engraftment of a vascularized human skin equivalent. Faseb J 2003;17:2250-6. http://dx.doi.org/10.1096/fi.03-0257com

17. Supp DM, Karpinski AC, Boyce ST. Vascular endothelial growth factor overexpression increases vascularization by murine but not human endothelial cells in cultured skin substitutes grafted to athymic mice. J Burn Care Rehabil 2004;25:337-45. http://dx.doi.org/10.1097/01.BCR.0000132168.02947.A1

18. Magnan $M$, Levesque $P$, Gauvin $R$, et al. Tissue engineering of a genitourinary tubular tissue graft resistant to suturing and high internal pressures. Tissue Eng Part A 2009;15:197-202. http://dx.doi. org/10.1089/ten.tea.2007.0303

19. Bouhout S, Perron E, Gauvin $R$, et al. In vitro reconstruction of an autologous, watertight, and resistant vesical equivalent. Tissue Eng Part A 2010;16:1539-48. http://dx.doi.org/10.1089/ten.TEA.2009.0473

20. Bouhout $S$, Gauvin $R$, Gibot $L$, et al. Bladder substitute reconstructed in a physiological pressure environment. J Pediatr Urol 201 1;7:276-82. http://dx.doi.org/10.1016/i.jpurol.2011.03.002

21. Cattan V, Bernard G, Rousseau A, et al. Mechanical stimuli-induced urothelial differentiation in a human tissue-engineered tubular genitourinary graft. Eur Urol 2011;60:1291-8. http://dx.doi.org/10.1016/i. eururo.2011.05.051

22. Germain $L$, Rouabhia $M$, Guignard $R$, et al. Improvement of human keratinocyte isolation and culture using thermolysin. Burns 1993;19:99-104. http://dx.doi.org/10.1016/0305-4179(93)90028-7

23. Magnan M, Berthod F, Champigny M.F, et al. In vitro reconstruction of a tissue-engineered endothelialized bladder from a single porcine biopsy. J Pediatr Urol 2006;2:261-70. http://dx.doi.org/10.1016/i. ipurol.2005.11.019

24. L'Heureux N, Germain L, Labbe R, et al. In vitro construction of a human blood vessel from cultured vascular cells: a morphologic study. J Vasc Surg 1993;17:499-509. http://dx.doi.org/10.1016/07415214(93)90150-K

25. Imbeault A, Bernard $G$, Ouellet $G$, et al. Surgical option for the correction of Peyronie's disease: an autologous tissue-engineered endothelialized graft. J Sex Med 2011;8:3227-35. http://dx.doi. org/10.1111/j.1743-6109.2011.02374.x

26. Freytes $\mathrm{DO}$, Tullius $\mathrm{RS}$, Valentin JE, et al. Hydrated versus lyophilized forms of porcine extracellular matrix derived from the urinary bladder. J Biomed Mater Res A 2008;87:862-72. http://dx.doi.org/10.1002/ jbm.a.31821

27. Allman AJ, McPherson TB, Badylak SF, et al. Xenogeneic extracellular matrix grafts elicit a TH2-restricted immune response. Transplantation 2001;71:1631-40. http://dx.doi.org/10.1097/00007890200106150-00024

28. Guan $Y, O u$ L, Hu G, et al. Tissue engineering of urethra using human vascular endothelial growth factor gene-modified bladder urothelial cells. Artif Organs 2008;32:91-9. http://dx.doi.org/10.1111/i.15251594.2007.00502.x

29. Hudon V, Berthod F, Black AF, et al. A tissue-engineered endothelialized dermis to study the modulation of angiogenic and angiostatic molecules on capillary-like tube formation in vitro. $\mathrm{Br} J$ Dermatol 2003;148:1094-104. http://dx.doi.org/10.1046/i.1365-2133.2003.05298.x

30. Guillemette MD, Gauvin R, Perron C, et al. Tissue-engineered vascular adventitia with vasa vasorum improves graft integration and vascularization through inosculation. Tissue Eng Part A 2010;16:2617-26. hitp://dx.doi.org/10.1089/ten.tea.2009.0612

31. Black AF, Berthod F, L'Heureux N, et al. In vitro reconstruction of a human capillary-like network in a tissue-engineered skin equivalent. Faseb J 1998;12:1331-40.

Correspondence: Dr. Stéphane Bolduc, LOEX, Aile-R Centre Hospitalier Affilié Universitaire de Québec, 1401 18e Rue, Québec, QC G1J 124; fax: 418-990-8248; stephane.bolduc@fmed.ulaval.ca 